\title{
Lung cancer growth inhibition and autophagy activation by tetrazole via ERK1/2 up-regulation and $\mathrm{mTOR} / \mathrm{p} 70 \mathrm{~S} 6 \mathrm{~K}$ signaling down-regulation
}

\author{
Liangjian Zheng $1,2 \#$, Jun Zhang ${ }^{1,2 \#}$, Jia Fan 1,2, Yuxin He1,2, Tingting Zhan 1,2, Liwen Rong1,2, \\ Mengzhen Yuan ${ }^{1,2}$ and Hongyan Zhang ${ }^{3 \otimes}$
}

1Department of Oncology, The Third People's Hospital of Chengdu, Chengdu, Sichuan, 610031, China; 2 Department of Oncology, The Affiliated
Hospital of Southwest Jiaotong University, Chengdu, Sichuan, 610031, China; 3Department of Laboratory Medicine, Eastern Hospital, Sichuan Academy of Medical Sciences \& Sichuan Provincial People's Hospital, Chengdu, Sichuan, 610101, China

Lung cancer, a most common clinically diagnosed malignancy grows rapidly and undergoes metastasis/diffusion to distant organs at a fast rate. In the present study gravacridondiol tetrazole (tetrazole) was synthesized and investigated for lung cancer growth inhibition potential in vitro. MTT assay and flow cytometry using propidium iodide were used to determine viability changes and DNA content distribution. Protein expression and apoptotic changes were detected by western blotting and Annexin-V/PI assays. Treatment with $12 \mu \mathrm{M}$ tetrazole suppressed viabilities to $23 \%$ and $20 \%$ in $\mathrm{A} 549$ and $\mathrm{NCl}-\mathrm{H} 1819$ cells, respectively. In tetrazole exposed cells, G1-phase cell count increased significantly compared to the control. Tetrazole-treatment of A549 and $\mathrm{NCl}-\mathrm{H} 1819$ cells caused a prominent raise in LC3-II and p-ERK1/2 expression at $72 \mathrm{~h}$. The SQSTM1/p62 level, p-mTOR and p-p70S6K expression was lowered significantly in A549 and $\mathrm{NCl}-\mathrm{H} 1819$ cells on exposure to tetrazole. Exposure to U1026 alleviated tetrazole mediated LC3II/I ratio increase in A549 and $\mathrm{NCl}-\mathrm{H} 1819$ cells significantly $(P<0.02)$ compared to tetrazole treated cells. Treatment with tetrazole and 3-MA in combination led a significant $(P<0.02)$ elevation in $\mathrm{A} 549$ and $\mathrm{NCl}-\mathrm{H} 1819$ cell apoptotic count relative to tetrazole $(12 \mu \mathrm{M})$ alone treated cells. Moreover, tetrazole and 3-MA combination increased cleavage of caspase- 3 to a greater extent compared to tetrazole. In summary, tetrazole manifested antiproliferative effect on lung cancer cells via autophagy over-activation and arrest of cell cycle. It deactivated ERK1/2 signalling and promoted $\mathrm{mTOR}$ signaling in A549 and $\mathrm{NCl}-\mathrm{H} 1819$ cells to regulate cancer proliferation. Thus, tetrazole needs to be studied further as an anti-proliferative agent for treatment of lung cancer.

Keywords: tetrazoles, autophagy, metastasis, anti-proliferative, apoptosis

Received: 09 July, 2021; revised: 08 August, 2021; accepted: 30 August, 2021; available on-line: 28 February, 2022

凶e-mail: zhanghongyan0311@163.com

\#These two authors contributed to this work equally

Abbreviations: TGF- $\beta$, Transforming growth factor- $\beta$ (TGF- $\beta$ ): DMEM, Dulbecco's modified Eagle's medium; MTT, 3-(4,5-dimethylthiazol-2-yl)-5-(3-carboxymethoxyphenyl)-2-(4-sulfophenyl)-2Htetrazolium; BrdU, bromodeoxyuridine; PDGFRs, Platelet-derived growth factor receptors

\section{INTRODUCTION}

Lung cancer, a most common clinically diagnosed malignancy worldwide is detected in two forms: small cell lung cancer (SCLC) and non-small cell lung cancer (NSCLC) (Seymore, 1999). SCLC has been reported to grow rapidly and undergo metastasis/diffusion to distant organs at much faster rate compared to NSCLC (Yang et al., 2009). During the last few decades, several countries including China reported a drastic increase in incidence as well as mortality rate of the lung cancer. Although etiology of lung cancer is not clearly known, reports have found close association of pulmonary cancer with long-term smoking (Bekhit et al., 2004). Among globally diagnosed lung cancer patients $\sim 80 \%$ cases account for NSCLC. Clinically it has been demonstrated that there is post-operative recurrence in most of the NSCLC patients undergoing treatment (Bekhit et al., 2004). Patients suffering from advanced stage of NSCLC have very poor prognosis (Shimizu et al., 2004) and therefore effective strategies are needed to control lung cancer development.

Autophagy, a cellular homeostasis process, plays a key role in degradation of dysfunctional/unnecessary contents-proteins or organelles in living beings (Bolt et al., 2012). Autophagy regulates survival response and its over-activation induced by pathogen associated mechanism or due to nutrient starvation becomes fatal for cells as it leads to cell death via a non-apoptotic pathway (Klionsky, 2014). A signalling mechanism identified for autophagy activation in mammalian cells involves mammalian target of rapamycin (mTOR) pathway (Wang et al., 2008). Activation of $\mathrm{PI} 3 \mathrm{~K} / \mathrm{AKT} / \mathrm{mTOR}$ signalling has been identified to promote growth, proliferation, and metastasis in different kinds of cancers (Santoni et al., 2013). However, targeting $\mathrm{PI} 3 \mathrm{~K} / \mathrm{AKT} / \mathrm{m}$ TOR pathway has been revealed as an appropriate strategy to regulate tumor development (Nazio et al., 2013). Additionally, autophagy activation is also linked to the extracellular signal-regulated kinases 1/2 (ERK1/2) (Hosokawa et al., 2009).

Tetrazole fragment constitutes a promising pharmacophore and is being synthesized in many compounds to improve bioactivity in drug development program (Favata et al., 1998). Flexibility combined with stability on binding to various targets is the main factor which led to advances in tetrazole chemistry (Fukazawa et al., 2002). Another characteristic property that attracts towards tetrazoles as pharmacophores is their ability to act 
as carboxylic functionality mimicking agents. Because of this property tetrazoles showed effective anti-inflammatory potential (Sharma et al., 2018) and act as analgesics and antiulcer agents (Tang et al., 2017). Gravacridondiol is isolated from Ruta graveolens $L$. that is a perennial herb, originally native of the Mediterranean region (Tanida, 2011). Formulations of $R$ graveolens have been used to inhibit progression or to completely repress the glioma growth in human brains without causing toxicity (Klionsky et al., 2012). In the present study gravacridondiol tetrazole (tetrazole) was synthesized and investigated for lung cancer growth inhibition potential in vitro. Additionally, the mechanism associated with tetrazole mediated cell death was also explored.

\section{MATERIALS AND METHODS}

\section{Cell culture}

Beas-2B normal epithelial lung cells, A549 and NCI-H1819 lung cancer cell lines were procured from ATCC (Manassas, VA, USA) and grown in DMEM (HyClone, Logan, UT) mixed with FBS (10\%). Medium was also mixed with penicillin $(100 \mathrm{U} / \mathrm{mL})$ and streptomycin $(100 \mathrm{mg} / \mathrm{mL})$. The cells were incubated overnight at $37^{\circ} \mathrm{C}$ in an incubator under $5 \% \mathrm{CO}_{2}$ and $95 \%$ air atmosphere.

\section{Synthesis of gravacridondiol tetrazole (tetrazole)}

R. graveolent plant material was obtained from the China-Ladakh boarder and identified by Prof. Zhang Li. Roots of the plant were dried under shade, chopped, and then finely powdered in grinders to collect the powder. The powdered plant material was extracted in ethyl acetate solvent for $48 \mathrm{~h}$, the solvent was decanted and concentrated in rotary vacuum evaporator to obtain the extract. The extract was mixed with silica gel to prepare slurry, which was loaded onto a silica gel column to isolate the gravacridondiol compound.

The solution of gravacridondiol in aqueous alcohol was treated with 1,3-diiodo-5,5-dimethylhydantoin (2 equivalent; DIH) in the dark at $70^{\circ} \mathrm{C}$ for $12 \mathrm{~h}$. The crude nitrile compound (2; Scheme 1) was purified by column chromatography, dried, and then weighed. The nitrile (2; Scheme 1) obtained was dissolved in DMF and then reacted with sodium azide ( 2 equivalent) and iodine $(6 \mathrm{~mol} \%)$ for $24 \mathrm{~h}$ at $60^{\circ} \mathrm{C}$ to obtain the desired tetrazole (3; Scheme 1). Impure tetrazole (3; Scheme 1) was loaded onto a column and purified using ethyl acetate/ petroleum ether (50:50) solvent system. Tetrazole was characterized using spectral techniques like $1 \mathrm{H}$ NMR, HRMS and IR spectroscopy.

\section{Viability assay}

The cellular density in 96-well plates was adjusted at $2 \times 10^{5}$ cells/well and grown for overnight in an incubator at $37^{\circ} \mathrm{C}$. Tetrazole at $1.5,3,6$ and $12 \mu \mathrm{M}$ was mixed with DMEM and cell incubation was performed for 72 $h$ with it. Then, medium from the wells was replaced by fresh medium free from tetrazole. Afterwards, MT'T solution $(0.5 \mathrm{mg} / \mathrm{ml})$ was poured into each well and incubation of cells was carried out for 4 more hours under the same conditions. Discarding of medium from the wells was followed by an addition of $100 \mu$ l DMSO solubilization solution. Gentle shaking of plates to uniformly mix the colour was followed by optical density measurements, in triplicates, at $570 \mathrm{~nm}$ using the microplate reader (Wellscan MK3, Labsystems, Finland).

\section{Cell cycle analysis}

The cells were distributed at $2 \times 10^{4}$ cells/ well density in 6-well plates and cultured for overnight at $37^{\circ} \mathrm{C}$. Cellular distribution in different phases was detected following propidium iodide (Sigma-Aldrich) dyeing of the DNA content. Briefly, trypsinization and then overnight fixing in $70 \%$ ethyl alcohol were followed by PBS-washing of the cells two times. Afterwards, centrifugation was performed at $235 \times \mathrm{g}$ and the separated cells were treated for $15 \mathrm{~min}$ with RNase $(50 \mu \mathrm{l})$ prior to PI $(50 \mu \mathrm{g} / \mathrm{ml})$ staining for $2 \mathrm{~h}$. The FACSAria II instrument for flow cytometry and CellQuest7.6.2 software (BD Biosciences, CA, USA) was employed for the determination of cell fraction in various cell cycle phases.

\section{Western blotting}

The cells were distributed at $2 \times 10^{4}$ cells/well density in 6-well plates and incubated with tetrazole at 6 and 12 $\mu \mathrm{M}$ for $72 \mathrm{~h}$. Exposure to tetrazole was followed by cell washing two times with cold-PBS and treatment with lysis buffer consisting of NP-40 (1\%), sodium phosphate $(5 \mathrm{mM})$, sodium chloride (150), Tris- $\mathrm{HCl}(\mathrm{pH} 7.5$; $20 \mathrm{mM}), \mathrm{Na}_{3} \mathrm{VO}_{4}(5 \mathrm{mM})$, PMSF $(1 \mathrm{mM})$ and leupeptin $(10 \mu \mathrm{g} / \mathrm{ml})$. Lysate formed after $30 \mathrm{~min}$ was centrifuged for $20 \mathrm{~min}$ at $15000 \times \mathrm{g}$ to collect the supernatants in which protein content was estimated by BCA kits. Samples were loaded in equal amounts $(20 \mu \mathrm{g})$ to resolve bands on 12\% SDS-PAGE followed by transfer onto the PVDF-membranes. Membrane incubation was made at $4^{\circ} \mathrm{C}$ with primary antibodies overnight, followed by PBS/Tween 20 washing for $1 \mathrm{~h}$. Afterwards, incubation was carried out with the secondary antibodies conjugated to the goat anti-rabbit $\mathrm{IgG}$ for $2 \mathrm{~h}$ at room temperature. Band visualization was made using SignalFire ${ }^{\text {TM }}$ ECL Reagent (Cell Signaling Technology, Inc.) and quantification by Image J version 2.0 software (Bio-Rad Laboratories Inc, USA). Antibodies used were against: p-ERK1/2 (dilution 1:1200), LC3 (dilution 1:1200), sequestosome-1 (SQSTM1/p62; dilution 1:2000), ERK1/2 mTOR (dilution 1:1200), p-mTOR (dilution 1:1200), p-p70S6K (dilution 1:2000) and $\beta$-actin (dilution 1:1200; all from Cell Signaling Technology, Inc., Danvers, MA, USA).

\section{Apoptosis assays}

Cells were seeded at $2 \times 10^{4}$ cells/well density in 6-well plates and incubated with tetrazole at $12 \mu \mathrm{M}$ for $72 \mathrm{~h}$. Cells exposed to tetrazole were stained as per instructions of the supplier with Annexin V/PI (BD Biosciences, NJ, USA) for apoptosis detection. Incubation of A549 and NCI-H1819 cells with Annexin-V/PI was performed in the dark for $20 \mathrm{~min}$. Then, apoptosis was observed in cells by a flow cytometer (BD Biosciences, NJ, USA) and data obtained was analysed using WinMDI version 2.5.

\section{Statistical analysis}

Data analysis was made using SPSS version-17.0 software (SPSS, Inc., Chicago, IL, USA). All the data obtained in present study are expressed as the mean \pm standard deviations of triplicate measurements. One-way analysis of variance (ANOVA) and Tukey's post-hoc test was used for statistical analysis of the data. At $P<0.05$ differences denoted statistically significant differences. 


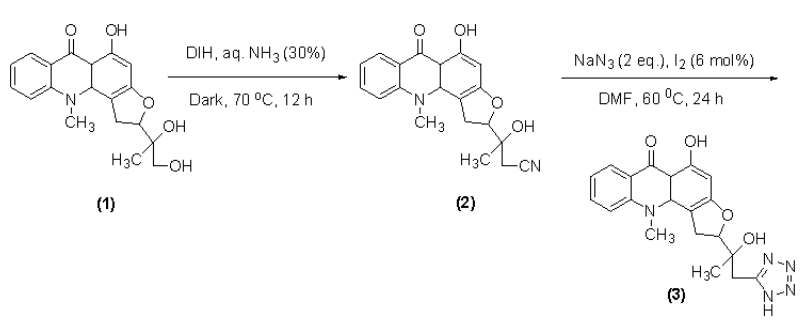

Scheme 1. Synthesis of the gravacridondiol tetrazole.

\section{RESULTS}

\section{Tetrazole suppresses A549 and $\mathrm{NCl}-\mathrm{H} 1819$ cell viability}

Tetrazole was synthesised in two steps from gravacridondiol using 1,3-diiodo-5,5-dimethylhydantoin (DIH) as reagent (Scheme 1). Viability changes by tetrazole at $0.75,1.5,3,6$ and $12 \mu \mathrm{M}$ in A549 and NCI-H1819 cells were measured using MT'T assay (Fig. 1). In tetrazoletreated cells a significant $(P<0.05)$ suppression in viability was measured in dose-based manner with an increase in the tetrazole concentration. Tetrazole treatment of A549 and NCI-H1819 cells suppressed viabilities to $89 \%$ and $86 \%$, respectively at $0.75 \mu \mathrm{M}$ concentration. Treatment with $12 \mu \mathrm{M}$ tetrazole suppressed viabilities to $23 \%$ and 20\%, respectively in A549 and NCI-H1819 cells. Tetrazole treatment did not affect the viability of Beas2B normal epithelial lung cells (not shown).

Tetrazole leads to $\mathrm{A} 549$ and $\mathrm{NCl}-\mathrm{H} 1819$ cell cycle arrest in G1-phase

Tetrazole exposure at 6 and $12 \mu \mathrm{M}$ for $72 \mathrm{~h}$ was followed by flow cytometric detection of A549 and NCIH1819 cells for cell cycle changes (Fig. 2A, B). In 12

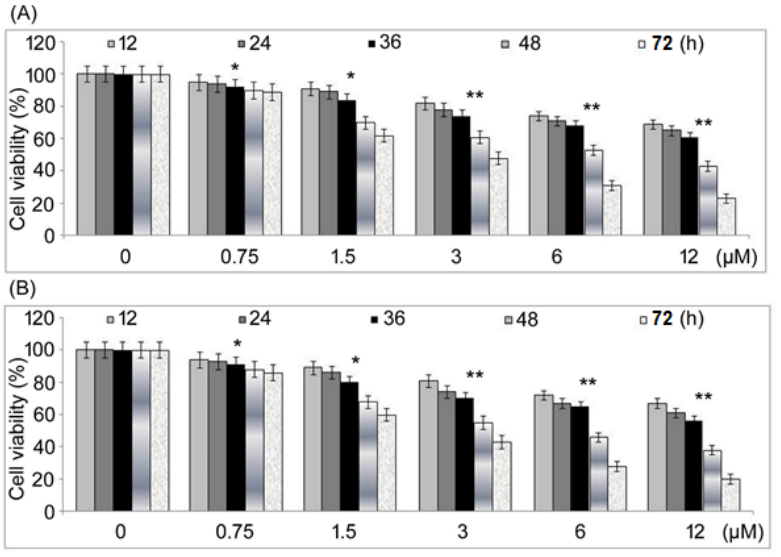

Figure 1. Effect of tetrazole on A549 and $\mathrm{NCl}-\mathrm{H} 1819$ cell viability.

Exposure to tetrazole at $0.75,1.5,3,6$ and $12 \mu \mathrm{M}$ was followed by determination of viability changes in (A) A549 and (B) NCI-H1819 cells at $12,24,36,48$ and $72 \mathrm{~h}$. ${ }^{*} P<0.05,{ }^{*} P<0.02$ vs. without tetrazole.

$\mu \mathrm{M}$ tetrazole exposed A549 cells, G1-phase cell count increased to $71.44 \pm 3.98 \%$ compared to $43.76 \pm 3.14 \%$ in control. In NCI-H1819 cells tetrazole exposure at $12 \mu \mathrm{M}$ raised G1-phase cell population to $75.72 \pm 4.52 \%$ compared to $43.86 \pm 3.61 \%$ in the control. Tetrazole exposure caused significant $(P<0.05)$ lowering of cell population in $\mathrm{S}$ and G2/M phases in A549 and NCI-H1819 cells at $72 \mathrm{~h}$.

\section{Tetrazole promotes LC3-II and lowers SQSTM1/p62 in A549 and $\mathrm{NCl}-\mathrm{H} 1819$ cells}

In tetrazole-treated A549 and NCI-H1819 cells a prominent raise in LC3-II expression was observed at $72 \mathrm{~h}$ relative to control (Fig. 3). Tetrazole induced LC3-II expression increase was higher in $12 \mu \mathrm{M}$ exposed
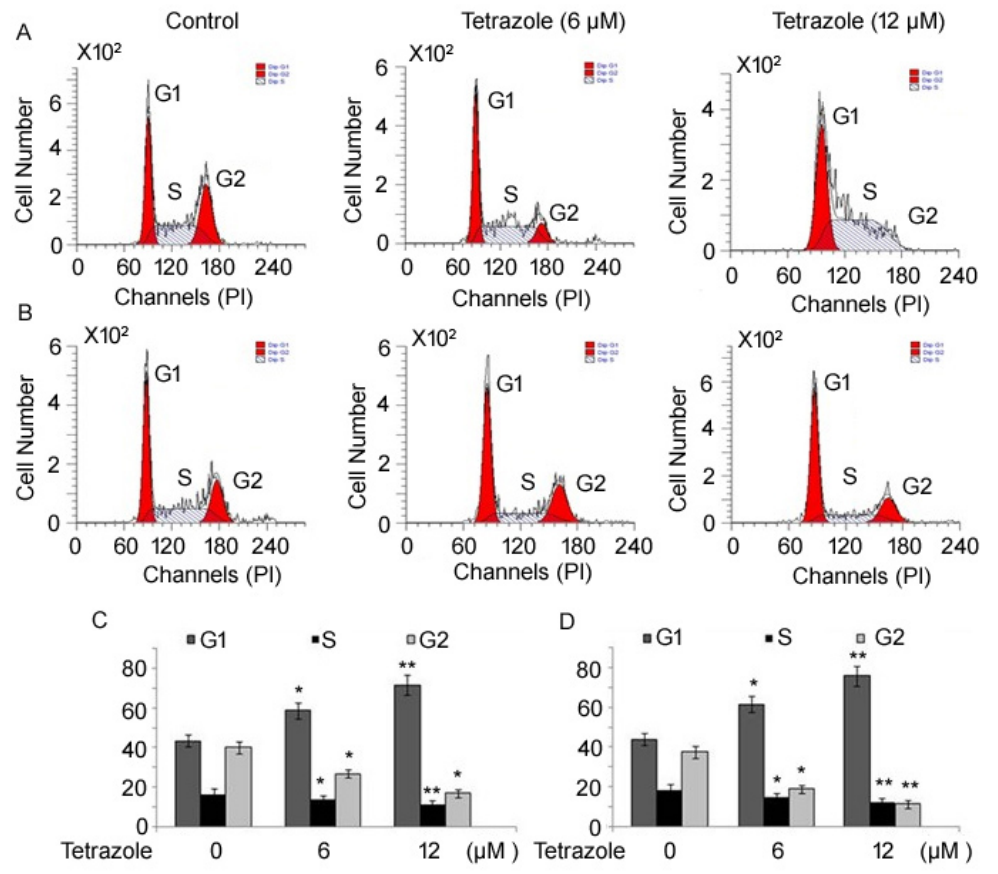

Figure 2. Effect of tetrazole on $\mathrm{A} 549$ and $\mathrm{NCl}-\mathrm{H} 1819$ cell cycle.

Exposure to tetrazole at 6 and $12 \mu \mathrm{M}$ was followed by flow cytometry for detection of DNA content in (A, C) A549 and (B, D) NCl-H1819 cells at 72 h. ${ }^{*} P<0.05,{ }^{* *} P<0.02$ vs. without tetrazole. 

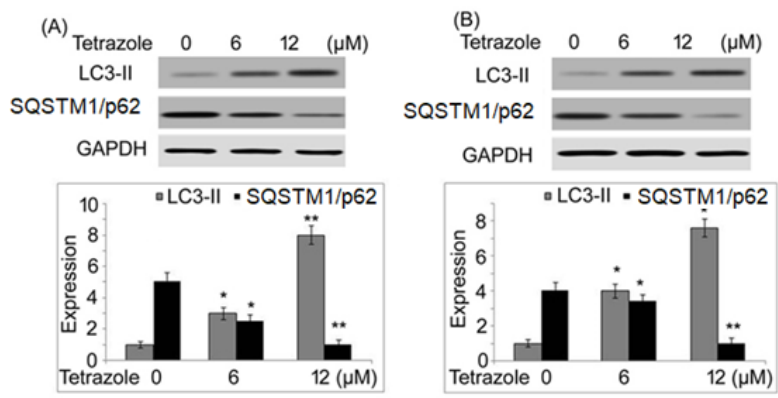

Figure 3. Effect of tetrazole on autophagy markers in A549 and $\mathrm{NCl}-\mathrm{H} 1819$ cells.

Exposure to tetrazole at 6 and $12 \mu \mathrm{M}$ was followed by assessment of LC3-II and SQSTM1/p62 expression in (A) A549 and (B) NCl$\mathrm{H} 1819$ cells at $72 \mathrm{~h} .{ }^{*} P<0.05,{ }^{* *} P<0.02$ vs. control.

A549 and NCI-H1819 cells compared to cells exposed to $6 \mu \mathrm{M}$. The level of SQSTM1/p62 expression showed a marked lowering in A549 and NCI-H1819 cells on exposure to tetrazole. Lowering of SQSTM1/p62 expression by tetrazole treatment was more prominent in $12 \mu \mathrm{M}$ treated A549 and NCI-H1819 cells relative to 6 $\mu \mathrm{M}$ exposed cells.

\section{Tetrazole regulates ERK1/2 and mTOR phosphorylation in $\mathrm{A} 549$ and $\mathrm{NCl}-\mathrm{H} 1819$ cells}

The p-ERK1/2 level showed a prominent enhancement in A549 and NCI-H1819 cells on exposure to tetrazole at 6 and $12 \mu \mathrm{M}$ (Fig. 4A). In $12 \mu \mathrm{M}$ tetrazole treated cells, p-ERK1/2 expression was enhanced to maximum level compared to $6 \mu \mathrm{M}$ treated A549 and NCI-H1819 cells. Exposure of A549 and NCIH1819 cells to 6 and $12 \mu \mathrm{M}$ tetrazole significantly lowered p-mTOR expression at $72 \mathrm{~h}$ relative to the control (Fig. 4B). Treatment with tetrazole caused significant $(P<0.02)$ inhibition of $\mathrm{p}-\mathrm{p} 70 \mathrm{~S} 6 \mathrm{~K}$ expression in A549 and NCI-H1819 cells at 6 and $12 \mu \mathrm{M}$ doses.

\section{Tetrazole mediated LC3II/I increase in A549 and $\mathrm{NCl}-\mathrm{H} 1819$ cells is reversed by $\mathrm{U} 0126$}

Tetrazole treatment at $12 \mu \mathrm{M}$ significantly $(P<0.05)$ raised LC3II/I ratio in A549 and NCI-H1819 cells relative to control (Fig. 5). However, exposure to U1026 alleviated tetrazole mediated LC3II/I ratio increase in A549 and NCI-H1819 cells significantly $(P<0.02)$ compared to tetrazole treated cells.

\section{Tetrazole promotes $\mathrm{A} 549$ and $\mathrm{NCl}-\mathrm{H} 1819$ cell apoptosis}

Significant $(P<0.05)$ rise in apoptotic cell count was observed in A549 and NCI-H1819 cells on treatment with tetrazole at $12 \mu \mathrm{M}$ (Fig. 6). Exposure to 3-MA could not increase A549 and NCI-H1819 cell apoptotic percentage when compared to the control cells. Treatment with tetrazole $(12 \mu \mathrm{M})$ and 3-MA in combination led a significant $(P<0.02)$ elevation in A549 and NCIH1819 cell apoptotic count relative to tetrazole $(12 \mu \mathrm{M})$ alone treated cells.

\section{Tetrazole mediated A549 and NCl-H1819 cell apoptosis is elevated by $3-\mathrm{MA}$}

In A549 and NCI-H1819 cells tetrazole treatment promoted caspase-3 cleavage markedly at $12 \mu \mathrm{M}$ doses relative to control cells (Fig. 7). Exposure to 3-MA could not increase caspase-3 cleavage in A549 and NCI-H1819
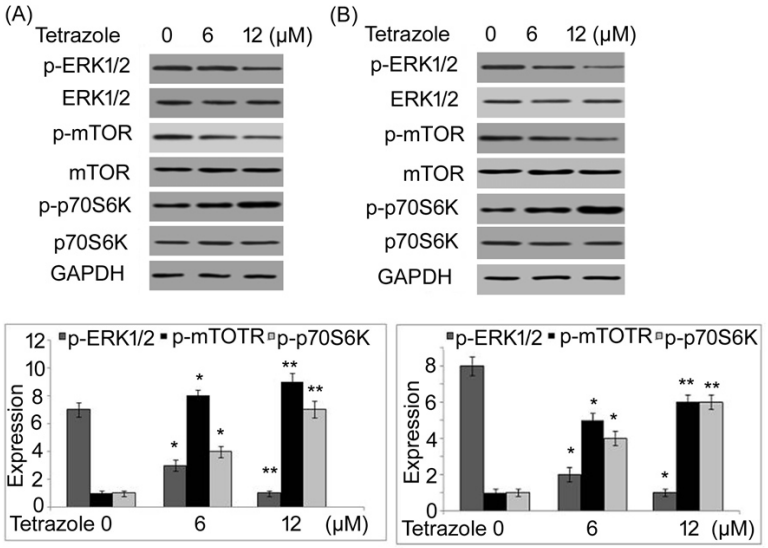

Figure 4. Effect of tetrazole on mTOR/ERK signalling in A549 and $\mathrm{NCl}-\mathrm{H} 1819$ cells.

Exposure to tetrazole at 6 and $12 \mu \mathrm{M}$ was followed by assessment of mTOR, ERK and p70S6K activation in (A) A549 and (B) NClH1819 cells. ${ }^{*} P<0.05,{ }^{* *} P<0.02$ vs. without tetrazole.
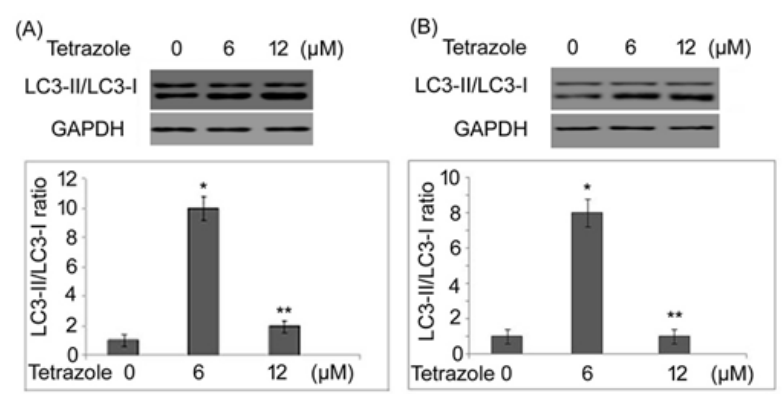

Figure 5. Effect of U1026 on tetrazole induced higher LC3II/I ratio.

A549 and $\mathrm{NCl}-\mathrm{H} 1819$ cells were treated with tetrazole at $12 \mu \mathrm{M}$ and then exposed to U1026 at $10 \mu \mathrm{M}$ doses for $72 \mathrm{~h}$. The LC3II and LC3I expression changes in (A) A549 and (B) NCl-H1819 cells were monitored by western blotting. ${ }^{*} P<0.05,{ }^{* *} P<0.02$ vs. without tetrazole.

cells. However, when A549 and NCI-H1819 cells were treated with tetrazole and 3-MA combination cleaved caspase-3 level showed marked up-regulation relative to tetrazole-treated cells.

\section{DISCUSSION}

Chemotherapeutic strategy for cancer has advanced into a novel era wherein molecular pathways are targeted using highly selective drugs that are free from conventional cytotoxicity (Bursch, 2001). Invented tetrazole derivatives were found to be highly active and yielded promising results as anti-cancer agents (Mihaylova et al., 2011). Compounds containing tetrazole rings have been demonstrated to exhibit diversity of biological activities (Pyo et al., 2012). The present study found that tetrazole repressed A549 and NCI-H1819 cancer cells viability depending upon the concentration added. Tetrazole exposed A549 and NCI-H1819 cells were examined by flow cytometry for possible changes in cell cycle progression. It was found that tetrazole exposure induced an arrest of cell cycle in A549 and NCI-H1819 cells in G1-phase. Tetrazole $(12 \mu \mathrm{M})$ exposure raised A549 and NCI-H1819 cell population from 43\% to more than $70 \%$ in the G1-phase. Consequently, significant $(P<0.05)$ lowering of cell population in $\mathrm{S}$ and 

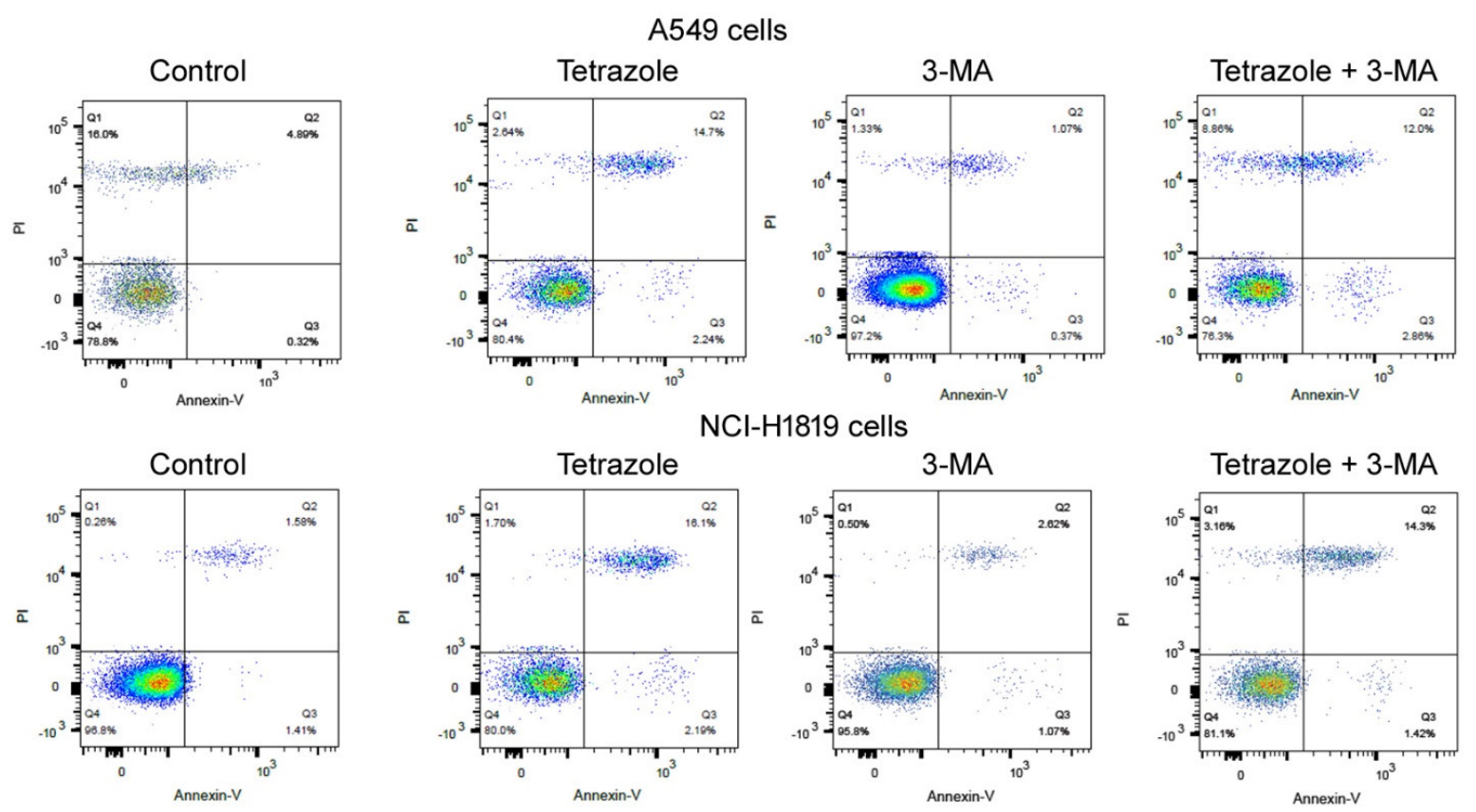

Figure 6. Effect of 3-MA and tetrazole on apoptosis.

A549 and $\mathrm{NCl}-\mathrm{H} 1819$ cells were treated with tetrazole at $12 \mu \mathrm{M}$ and then exposed to 3-MA at $5 \mu \mathrm{M}$ doses for 72 h. Apoptotic death in A549 and $\mathrm{NCl}-\mathrm{H} 1819$ cells was detected by Flow cytometry. ${ }^{*} P<0.05,{ }^{* *} P<0.02$ vs. without tetrazole.

G2/M phases was found in tetrazole exposed A549 and NCI-H1819 cells.

Autophagy is actually a process of homeostasis associated with delivery of various intracellular constituents to be degraded into the lysosomes. Besides several environmental stresses, chemotherapeutics also activate autophagy in tumor cells in different organs (Schmidt-Kittler et al., 2010). Over-activated autophagy acts as another process to eliminate cells in programmed but nonapoptotic way (Kharas et al., 2010). A prominent marker indicating autophagy activation is the expression of LC-3 formed from LC3-I (Dancey et al., 2012). There is also a reduction in p62 level because of its degradation along with other autophagosomal contents during autophagy activation (Cagnol et al., 2010). In the present study tetrazole-treatment of A549 and NCI-H1819 cells led to a prominent raise in LC3-II expression relative to control cells. Moreover, tetrazole mediated LC3-II expression increase was higher in $12 \mu \mathrm{M}$ exposed A549 and NCI-H1819 cells compared to the cells exposed to $6 \mu \mathrm{M}$. Additionally, SQSTM1/p62 level showed a

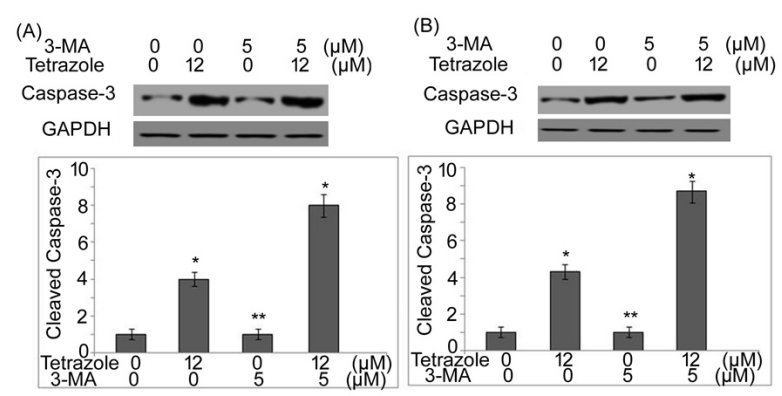

Figure 7. Effect of 3-MA and tetrazole on caspase-3 activation. A549 and $\mathrm{NCl}-\mathrm{H} 1819$ cells were treated with tetrazole at $12 \mu \mathrm{M}$ and then exposed to 3-MA at $5 \mu \mathrm{M}$ doses for $72 \mathrm{~h}$.

Activated caspase-3 was examined in (A) A549 and (B) NCl-H1819 cells by western blotting. ${ }^{*} P<0.05,{ }^{* *} P<0.02$ vs. without tetrazole. remarkable lowering in A549 and NCI-H1819 cells on exposure to tetrazole. This indicates that tetrazole treatment over-activates autophagy in A549 and NCI-H1819 cells, leading to growth inhibition.

Autophagy induction associated with nutrient starvation or other stress factors is regulated mainly by two pathways such as mTOR and ERK1/2 (Popova et al., 2017). Elevation in p-ERK expression in bladder (J82 \& 5637 cells) and adrenocortical carcinoma cells has been demonstrated to over-activate autophagy and inhibit tumor growth (Bachar et al., 2004). It is reported that mTORC1 avoids autophagy via deactivation of proteins and induction of mTOR and p70S6Kinase- 1 phosphorylation (Natrajan et al., 2010). In the present study p-ERK1/2 level showed a prominent enhancement in A549 and NCI-H1819 cells on exposure to tetrazole at 6 and $12 \mu \mathrm{M}$. Exposure of A549 and NCI-H1819 cells to 6 and $12 \mu \mathrm{M}$ tetrazole significantly lowered p-mTOR expression at $72 \mathrm{~h}$ relative to the control. Treatment with tetrazole caused significant $(P<0.02)$ inhibition of $\mathrm{p}$ p70S6K expression in A549 and NCI-H1819 cells at 6 and $12 \mu \mathrm{M}$ doses.

Inhibition of MEK1/MEK2 belonging to MAPK/ ERK kinases is achieved in a highly selective manner using U0126 (Hallinan et al., 2002). It is established that U0126 effectively blocks ERK pathway (Meepagala et al., 2005) and because of this A549 and NCI-H1819 cells were exposed to U0126 to confirm tetrazole mediated ERK1/2 activation. In the present study tetrazole treatment significantly $(P<0.05)$ raised LC3II/I ratio in A549 and NCI-H1819 cells relative to control. However, exposure to U1026 alleviated tetrazole mediated LC3II/I ratio increase in A549 and NCI-H1819 cells significantly $(P<0.02)$ compared to tetrazole treated cells.

Autophagy mediated cell death has been confirmed previously in carcinoma cells during antineoplastic studies (Pathak et al., 2003). The present study used 3-MA to block tetrazole mediated autophagy induction and investigate any increase in cell apoptosis. A significant 
$(P<0.05)$ rise in apoptotic cell count in A549 and NCIH1819 cells was observed on treatment with tetrazole. Exposure to 3-MA could not increase A549 and NCIH1819 cell apoptotic percentage when compared to the control cells. Treatment with a combination of tetrazole $(12 \mu \mathrm{M})$ and 3 -MA led to a significant $(P<0.02)$ elevation in A549 and NCI-H1819 cell apoptotic count relative to tetrazole alone treated cells. These finding indicated that tetrazole inhibited A549 and NCI-H1819 cell growth via autophagy activation. In A549 and NCI-H1819 cells tetrazole treatment promoted caspase- 3 cleavage markedly at $12 \mu \mathrm{M}$ doses relative to control cells. Exposure to 3-MA could not increase caspase- 3 cleavage in A549 and NCI-H1819 cells. However, when A549 and NCI-H1819 cells were treated with tetrazole and 3-MA combination, cleaved caspase-3 level showed marked up-regulation relative to tetrazole-treated cells.

\section{CONCLUSION}

In summary, tetrazole manifested anti-proliferative effect on lung cancer cells via autophagy over-activation and the arrest of cell cycle. It deactivated ERK1/2 signalling and promoted mTOR signaling in A549 and NCI-H1819 cells to regulate cancer proliferation. Thus, tetrazole needs to be studied further as an anti-proliferative agent for the treatment of lung cancer.

\section{Acknowledgements}

Not applicable.

\section{Competing interests}

The authors declare that there is no conflict of interest to disclose.

\section{Statement of Ethics}

The approval for present study was obtained from the Research Ethics Committee, The Third People's Hospital of Chengdu, Sichuan, China. All the experimental procedures were conducted in accordance with the guidelines issued by National Institute of Health (NIH), USA.

\section{SUMMARY}

Treatment with $12 \mu \mathrm{M}$ tetrazole suppressed viabilities to $23 \%$ and $20 \%$ in A549 and NCI-H1819 cells, respectively. In tetrazole exposed cells, G1-phase cell count increased significantly compared to the control. Tetrazoletreatment of A549 and NCI-H1819 cells caused a prominent raise in LC3-II and $\mathrm{p}-\mathrm{ERK} 1 / 2$ expression. The SQSTM1/p62 level, p-mTOR and p-p70S6K expression was significantly lowered in A549 and NCI-H1819 cells on exposure to tetrazole.

Exposure to U1026 alleviated tetrazole mediated LC3II/I ratio increase in A549 and NCI-H1819 cells significantly $(P<0.02)$ compared to tetrazole treated cells. Treatment with tetrazole and 3-MA in combination led a significant $(P<0.02)$ elevation in A549 and NCI-H1819 cell apoptotic count relative to tetrazole $(12 \mu \mathrm{M})$ alone treated cells. Tetrazole and 3-MA combination increased cleavage of caspase- 3 to a greater extent compared to tetrazole.

\section{Authors' contributions}

Hongyan Zhang conceived and designed the study, Liangjian Zheng, Jun Zhang, Jia Fan, Yuxin He, Tingting
Zhan performed experimental work and carried our literature survey. Liwen Rong, Liangjian Zheng and Jun Zhang compiled and analysed the data. Hongyan Zhang and Liangjian Zheng wrote the paper. All the authors approved the paper for publication.

\section{REFERENCES}

Bachar SC, Lahiri SC (2004) Synthesis of chloro and bromo substituted 5-(indan-1'-yl) tetrazoles and 5-(indan-1'-yl)methyltetrazoles as possible analgesic agents. Pharmazie 59: 435. https://doi.org/10.1002/ chin.200439118

Bekhit AA, El-Sayed OA, Aboulmagd E, Park JY (2004) Tetrazolo[1,5a]quinoline as a potential promising new scaffold for the synthesis of novel anti-inflammatory and antibacterial agents. Eur J Med Chem 39: 249-255. https://doi.org/10.1016/j.ejmech.2003.12.005.

Bolt AM, Zhao F, Pacheco S, Klimecki W'T (2012) Arsenite-induced autophagy is associated with proteotoxicity in human lymphoblastoid cells. Toxicol Appl Pharmacol 264: 255-261. https://doi. org/10.1016/j.taap.2012.08.006

Bursch W (2001) The autophagosomal-lysosomal compartment in programmed cell death. Cell Death Differ 8: 569-581. https://doi. org/10.1038/sj.cdd.4400852.

Cagnol S, Chambard JC (2010) ERK and cell death: Mechanisms of ERK-induced cell death-apoptosis, autophagy and senescence. FEBS J 277: 2-21. https://doi.org/10.1111/j.1742-4658.2009.07366.x

Dancey JE, Bedard PL, Onetto N, Hudson TJ (2012) The genetic basis for cancer treatment decisions. Cell 148: 409-420. https://doi. org/10.1016/j.cell.2012.01.014.

Favata MF, Horiuchi KY, Manos EJ, Daulerio AJ, Stradley DA, Feeser WS, Van Dyk DE, Pitts WJ, Earl RA, Hobbs F, Copeland RA, Magolda RL, Scherle PA, Trzaskos JM (1998) Identification of a novel inhibitor of mitogen-activated protein kinase kinase. J Biol Chem 273: 18623-18632. https://doi.org/10.1074/jbc.273.29.18623

Fukazawa H, Noguchi K, Murakami Y, Uehara Y (2002) Mitogen-activated protein/extracellular signal-regulated kinase kinase (MEK) inhibitors restore anoikis sensitivity in human breast cancer cell lines with a constitutively activated extracellular-regulated kinase (ERK) pathway. Mol Cancer Ther 1: 303-309. PMID: 12489846

Hallinan EA, Tsymbalov S, Dorn CR, Pitzele BS, Jr. Hansen DW (2002) Synthesis and biological characterization of L-N6-(1-iminoethyl)lysine 5-tetrazole-amide, a prodrug of a selective iNOS inhibitor. J Med Chem 45: 1686-1689. https://doi.org/10.1021/jm010420e

Hosokawa N, Hara T, Kaizuka T, Kishi C, Takamura A, Miura Y, Iemura S, Natsume T, Takehana K, Yamada N, Guan JL, Oshiro N, Mizushima N (2009) Nutrient-dependent mTORC1 association with the ULK1-Atg13-FIP200 complex required for autophagy. Mol Biol Cell 20: 1981-1991. https://doi.org/10.1091/mbc.e08-12-1248

Kharas MG, Okabe R, Ganis JJ, Gozo M, Khandan T, Paktinat M, Gilliland DG, Gritsman K (2010) Constitutively active Akt depletes hematopoietic stem cells and induces leukemia in mice. Blood 115: 1406-1415. https://doi.org/10.1182/blood-2009-06-229443.

Klionsky DJ, Abdalla FC, Abeliovich H, Abraham RT, AcevedoArozena A, Adeli K, Agholme L, Agnello M, Agostinis P, Aguirre-Ghiso JA et al. (2012) Guidelines for the use and interpretation of assays for monitoring autophagy. Autophagy 8: 445-544. https:// doi.org/10.4161/auto.19496

Klionsky DJ (2014) Coming soon to a journal near you-the updated guidelines for the use and interpretation of assays for monitoring autophagy. Autophagy 10: 1691. https://doi.org/10.4161/auto.36187

Meepagala KM, Schrader KK, Wedge DE, Duke SO (2005) Algicidal and antifungal compounds from the roots of Ruta graveolens and synthesis of their analogs. Phytochemistry 66: 2689-2695. https://doi. org/10.1016/j.phytochem.2005.09.019

Mihaylova MM, Shaw RJ (2011) The AMPK signalling pathway coordinates cell growth, autophagy and metabolism. Nat Cell Biol 13: 1016-1023. https://doi.org/10.1038/ncb2329

Natrajan U, Kaliappan I, Singh NK (2010) A facile design and efficient synthesis of schiff's bases of tetrazolo $[1,5-a]$ quinoxalines as potential anti-inflammatory and anti-microbial agents. Der PharmaChemica 21: 159-167. https://derpharmachemica.com/vol2-iss1..

Nazio F, Strappazzon F, Antonioli M, Bielli P, Cianfanelli V, Bordi M, Gretzmeier C, Dengjel J, Piacentini M, Fimia GM, Cecconi F (2013) mTOR inhibits autophagy by controlling ULK1 ubiquitylation, self-association and function through AMBRA1 and TRAF6. Nat Cell Biol 15: 406-416. https://doi.org/10.1038/ncb2708

Popova Elena EA, Protas V, TrifonovRostislav RE (2017) Tetrazole Derivatives as Promising-Anticancer Agent. Anti-cancer agents in Med Chem 17: 999. https://doi.org/10.2174/1871520617666170327143148

Pathak S, Multani AS, Banerji P, Banerji P (2003) Ruta 6 selectively induces cell death in brain cancer cells but proliferation in normal peripheral blood lymphocytes: A novel treatment for human brain cancer. Int J Oncol 23: 975-982. PMID: 12963976 
Pyo JO, Nah J, Jung YK (2012) Molecules and their functions in autophagy. Exp Mol Med 44: 73-80. https://doi.org/10.3858/ emm.2012.44.2.029

Schmidt-Kittler O, Zhu J, Yang J, Liu G, Hendricks W, Lengauer C Gabelli SB, Kinzler KW, Vogelstein B, Huso DL, Zhou S (2010) $\mathrm{PI} 3 \mathrm{~K} \alpha$ inhibitors that inhibit metastasis. Oncotarget 1: 339-348. https://doi.org/10.18632/oncotarget.166

Sharma A, O'Connor R, Celestino P, Killion S, Griswold-Krupski L, Bansal-Travers M (2019) Focus groups and in-depth interviews to guide the development of lung cancer screening informational materials. I Cancer Educ 34: 712-718. https://doi.org/10.1007/ s13187-018-1362-4

Santoni M, Amantini C, Morelli MB, Liberati S, Farfariello V, Nabissi M, Bonfili L, Eleuteri AM, Mozzicafreddo M, Burattini L, Berardi R, Cascinu S, Santoni G (2013) Pazopanib and sunitinib trigger autophagic and non-autophagic death of bladder tumour cells. $\mathrm{Br} J$ Cancer 109: 1040-1050. https://doi.org/10.1038/bjc.2013.420

Shimizu S, Kanaseki T, Mizushima N, Mizuta T, Arakawa-Kobayashi S, Thompson CB, Tsujimoto Y (2004) Role of Bcl-2 family proteins in a non-apoptotic programmed cell death dependent on autophagy genes. Nat Cell Biol 6: 1221-1228. https://doi.org/10.1038/ncb1192 Seymore L (1999) ovel anti-cancer agents in development: exciting prospects and new challenges. Cancer Treat Rev 25: 301-12. https:// doi.org/10.1053/ctrv.1999.0134

Tang Z, Li J, Shen Q, Feng J, Liu H, Wang W, Xu L, Shi G, Ye X, Ge M, et al. (2017) Contribution of upregulated dipeptidyl peptidase 9 (DPP9) in promoting tumorigenicity, metastasis and the prediction of poor prognosis in non-small cell lung cancer (NSCLC). Int J Cancer 140: 1620-1632. https://doi.org/10.1002/ijc.30571

Tanida I (2011) Autophagosome formation and molecular mechanism of autophagy. Antioxid Redox Signal 14: 2201-2214. https://doi. org/10.1089/ars.2010.3482

Wang SH, Shih YL, Ko WC, Wei YH, Shih CM (2008) Cadmium-induced autophagy and apoptosis are mediated by a calcium signaling pathway. Cell Mol Life Sci 65: 3640-3652. https://doi.org/10.1007/ s00018-008-8383-9

Yang R-Y, Ali SM, Ashwell MA, Kelleher E, Palma R, Westlund N (2009) US Patent, 2009; 0130117A1 